\title{
TO CLOUD OR NOT TO CLOUD?
}

\section{Richard S. Delaquis, Robert Morris University, rsdst5@mail.rmu.edu Guy Philbin, Robert Morris University, gxpst5@mail.rmu.edu}

\begin{abstract}
The central questions this paper seeks to address are: where the cloud intersects with a company's business Enterprise Architecture roadmap to success, how well it meets a company's strategy, vision, mission, and goal statements, and how it can be measured by the metrics defined in the company's business plan.
\end{abstract}

Keywords: Cloud computing, Enterprise Architecture, PaaS, IaaS, SaaS, Risk, Security.

\section{INTRODUCTION}

If one agrees with Scott that Enterprise Architecture (EA) should form a roadmap used to align business plans with Information Technology (IT), then the more accurate the roadmap, the easier it is for an organization to determine how to best evaluate cloud services. [1] However, roadmap alignment and implementation are not easy — especially within large organizations. Introduction of cloud computing has made alignment more complex as the cloud can provide infrastructure (IaaS), software (SaaS), and platform as a service (PaaS). It is an technology enabler that is flexible, on demand, just in time, and some say the road to the future.

Paul Fremantle of WSO2, a service enterprise that offers open source Carbon middleware, believes that EA is critical for robust cloud infrastructure: "So, for me, where you're going to have to move is to a complete platform that understands enterprise architecture. It isn't just about saying, 'I've got a web app and a database that are somehow provided in a cloud native fashion.'” [2] That said, the cloud is many things to many people: viable and profitable solution, a panacea, or an enigma.

\section{BACKGROUND}

Most businesses develop a plan that contains vision, mission, and goal statements which become a roadmap of how the company will progress to a determined level of success. If the company chooses to employ IT as an enabler in order to reach this level of success, Stenzel has pointed out that the challenge is to determine what IT should be acquired and how it should be used to meet the intent of the company's business plan. [3] If, as Scott argues, EA is the technology roadmap that aligns business with IT, how does this model square with the cloud? In this analysis, determining which portions of the roadmap that are candidates to be transferred to the cloud is the crux of how organizations should evaluate cloud computing.

\section{CLOUD COMPUTING}

The Information Technology Laboratory of the National Institute of Standards and Technology is on its fifteenth or so version of a definition of the cloud. [4] Ronald Kode's white paper on cloud security cites more than ten cloud definitions. [5] Not surprisingly, various definitions spring from engaged parties - universities, vendors, analysts, the government - all substantially different and sometimes proprietary. As expected, key players Microsoft, Google, and Cisco each offers a slightly different take as does almost every vendor competing for business touting the cloud environment:

- Verizon's CaaS allows customers to pay for data-center resources such as storage and application hosting dynamically. 


\section{Issues in Information Systems}

Volume XII, No. 1, pp. 54-58, 2011

- Amazon Elastic Compute Cloud (Amazon EC2) offers a web service that provides resizable compute capacity in the cloud.

- IBM CloudBurst is a prepackaged, self-contained, purpose-built service delivery platform.

Although describing the situation as swamp computing is emotionally satisfying, it does nothing to improve our tenuous understanding of the nature of what the cloud actually represents. Cloud computing is one of those portmanteau expressions that is evolving, hard to define, and comes in a wide variety of flavors that reflects a diverse array of environments, vendors, markets, and users: private, public, community, government, and hybrid.

So, for the moment at least, it seems safe to say that there is no consensus, no accepted definition, and no widespread agreement as to what constitutes the cloud. Nor, given the history of IT, should we realistically expect a conventionally accepted definition of cloud computing to emerge anytime soon.

\section{ENTERPRISE ARCHITECTURE}

While there is more general agreement as to what EA is and what it represents, there are also numerous definitions. Credited by some to be the person who coined of the term, Zachman defined EA as "that set of descriptive representations (i.e. 'Models') that are relevant for describing an Enterprise such that it can be produced to management's requirements (quality) and maintained over the period of its useful life (change).” [6] Weill and Ross defined it as "...the organizing logic for data, applications, and infrastructure, captured in a set of policies, relationships and technical choices to achieve desired business and technical standardization and integration." [7] The Gartner Group emphasizes business processes, organizational structure, and the technology used and defines EA as "the holistic expression of an organization's key business, information, application, and technology strategies and their impact on business functions and processes.” [8]

These definitions are not in lockstep, but all in all you get a sense that with EA form follows function in much the same way that the architect Louis Henry Sullivan defined his craft. EA uses an established framework to provide specific products or views to provide the graphical details, taxonomies and relationships for people, as well as process and technology for decision making. Many frameworks are used in both the public and private sector, including the Open Group Architecture Framework, the Zachman Architecture Framework, the Federal Enterprise Architecture, and the Department of Defense Architecture Framework. No matter what frame is used, well-designed architecture displays the vision and strategy of the company down to the data level. It is transparent throughout the organization, transcending divisional stovepipes, and is useful to all levels of the organization from technician through decision maker.

\section{ECONOMICS}

"The whole point of cloud computing is economy," according to cryptographer and security researcher Whitfield Diffie. [9] We concur but also must point out that it is very difficult to predict economics without a transparent infrastructure. Properly implemented EA can provide the who, what, when, where, and why of the business across the enterprise. But without knowing the business and its internal workings through its architecture, it is difficult for any business to make an informed judgment on whether or not cloud computing will be a positive addition to the bottom line. The rub that EA makes plain is that a cloud hides the underlying infrastructure. Although EA can provide a roadmap for the business from the vision, strategy, and goals, across systems, platforms and processes, all the way down to the data, the roadmap it provides will be incomplete if implementing a cloud service is not transparent. 


\section{Issues in Information Systems}

Volume XII, No. 1, pp. 54-58, 2011

RISK

A major concern with the cloud is risk. How business can mitigate risk in the cloud centers on risk aversion and total cost of ownership for the company. If you accept Lankhorst's definition of EA as "A coherent whole of principles, methods, and models that are used in the design and realization of the enterprise's organizational structure, business processes, information systems and infrastructure” than anything that operates outside of EA or that is not defined within EA is suspect. [10] It is suspect because stakeholders and decision makers must know how their business is running across the enterprise to be able to make intelligent decisions. As has been demonstrated many times, if stakeholders and decision makers are not informed due to a lack of business to IT alignment the business will soon serve as another example of an IT driven failure. So how does a company make an informed decision about SaaS, PaaS, and IaaS when investigating cloud services?

\section{PROCESS}

When making an informed decision about SaaS, how valuable are an organization's processes and to what degree are they proprietary are primary questions that must be addressed. Put another way, how much of an organization's processes can be successfully emulated within the cloud or translated to a ready-made solution? If the processes are already efficient and not people intensive, it may be better to retain them in house utilizing "as is" technology because they are a sunk cost and already paid for. However, if the company and the business are in a transitional mode, it may be advantageous to either re-engineer these processes to gain more efficiencies, pay a third party to analyze and streamline the processes, or utilize an off-the-shelf cloud solution so long as it meets all of the company's requirements. Licensing, number of users, instantiation counts are all factors that must be considered. Each course of action has associated risk and cost factors that must be identified up front when drafting any service agreement.

\section{WHAT IS ‘TO BE?’}

So what criteria should a company employ to determine if an organization should pass or invest in PaaS? In terms of this analysis, one of the most important benefits of PaaS is that it can help determine if it is cost effective to keep current platforms and technology or move on to an upgrade. Like heavily hyped 3D TV, new IT does not always live up to its initial promise. Each organization must carefully determine their own criteria in order to make a wise cloud decision. Decision makers must be informed and totally knowledgeable about all current systems capabilities and what the "to be" state should look like. Once that is established, each vendor and their products can be evaluated for form, fit, and function. In sum, PaaS can help answer how well a vendor and their equipment enhances a company's vision and culture and moves it forward along its roadmap to success.

\section{TRUST}

Transparency and trust are major factors when it comes to making a decision about IaaS. Here a business is presented with decisions as to how much of its equipment - hardware, software, and networks - it wants to outsource. Operationalizing the IaaS decision is fraught with questions: Does the company only pay for the usage of space for data taken up in the vendor's platform? Will the company be charged for every instantiation of a software application run on a vendor's platform? If the company is a transactional based organization, does the cost per transaction increase, decrease, or stay the same?

The key questions to be answered here are how much money an investment in outsourced infrastructure will save, how much will it earn, and how much of its business can be dependent and trusted to a vendor's service(s). The risks can be significant and include sustainability of the vendor, vendor modernization plans and budget, and the vendor's agility in supporting changes in business strategy, processes, and storage requirements. With a solid foundation utilizing an accurate and forward looking EA, those issues and their impacts can be played out in advance placing the company in a better position to bargain with or choose a vendor that comes closest to meeting the company's needs. 


\section{SECURITY}

Security is the common denominator that exists among SaaS, PaaS, and IaaS and remains a concern even as technology becomes more capable of operating with minimal human intervention. Greed, jealousy, revenge, and attention will continue to motivate some individuals to hack systems or steal secrets in search of financial or other gain. No matter what service they provide each cloud vendor has a responsibility for providing security. Third-party marketer Epsilon's security breech, which compromised customer's e-mail addresses and other private information, is a cogent example of security in the cloud gone bad.

Business leaders must be aware that with no industry standards for interoperability their investment is at risk. Organizations must understand that if they choose a vendor for service, it is not uncommon for a vendor to fail. Moreover, the complexity of the security equation increases when an organization mixes different services from different vendors. To meet these challenges, cloud security must be able to be architected by the vendor so that companies can compare their architecture against the vendor's architecture to ensure compatibility and determine whether or not investment in the cloud makes sense.

\section{SUMMARY}

Summarizing briefly, EA can provide a roadmap to business success when evaluating or utilizing the cloud. Each part of the cloud services outlined above can and should be analyzed: interfaces, conflicts, cost differentials, and "the cost and ROI of business" can be estimated or calculated so that stakeholders and decision makers can make informed decisions. Going forward, definitions need to be clarified and standards for interoperability need to be established.

Prior to adoption of cloud technology EA can provide a roadmap, solidify business to IT alignment within the cloud, and help address the questions of what the business wants to achieve. If that is accomplished, "To cloud or not to cloud?” is no longer a rhetorical question.

\section{CONCLUSION}

A business without true insight or knowledge of how it operates across the enterprise is like the famous Winchester Mystery House in San Jose California. Sarah Winchester started round-the-clock construction in 1884 and ceased 38 years later when she died. At her death, the house presented a magnificent facade to the world but the interior had 65 doors that opened to walls, 13 staircases to nowhere, and skylights built into the floor. A superstitious woman who received nightly instructions from ghosts employed about 140 builders to carry out her instructions without question. As she was her own architect, instead of fixing her ghostly foibles Mrs. Winchester simply built around them. Flawed architecture or uninformed cloud implementation are a roadmap to IT dysfunction and failure.

\section{REFERENCES}

1. Scott, J. (2010). Don't just build business-IT alignment, Map it. Retrieved from CIO website: http://www.cio.com/article/600576/Don_t_Just_Build_Business_IT_Alignment_Map_It?page=1\&taxonomy $\mathrm{Id}=3019$

2. Fremantle, P. (2011). Retrieved from Dana Gardner's BriefingsDirect: http://briefingsdirectblog.blogspot.com

3. Stenzel, J. (Ed.). (2007). CIO Best Practices. Hoboken, NY: John Wiley \& Sons Inc.

4. U.S. Commerce Department. The National Institute of Standards and Technology (NIST). The NIST Definition of Cloud Computing, Version 15, Peter Mell and Tim Grance, October 7, 2009. Retrieved from: http://www.nist.gov/itl/cloud/ 
5. Knode, R. (2009). Digital Trust in the Cloud: Liquid Security in Cloudy Places. Sterling, VA: Computer Sciences Corporation, 34.

6. Zachman, J. (1996). Enterprise Architecture: The issue of the century. 13. Retrieved from: http://www.aeablogs.org/eakd/files/EA_The_Issue_of the_Century.pdf, 5.

7. Weill, P., \& Ross, J. (2004). IT governance. Boston, MA: Harvard Business School Press, 30.

8. Gartner Group. (2009). Taxonomy and Definitions for the Multienterprise/B2B Infrastructure Model. ID Number: G00166095, 50.

9. Diffie, W. (2011). Technology Review. Retrieved from http://www.technologyreview.com/computing/23951/?a=f

10. Lankhorst, M. (2009). Enterprise Architecture at work (Second ed.). Berlin, Germany: Springer, 3. 